В. А. Рубан, Р. В. Цатурян. Анализ влияния государственной национальной политики на межнациональные отношения (на примере Новосибирской области)

УДК 316.47

DOI 10.18101/2304-4446-2020-3-41-49

\title{
АНАЛИЗ ВЛИЯНИЯ ГОСУДАРСТВЕННОЙ НАЦИОНАЛЬНОЙ ПОЛИТИКИ \\ НА МЕЖНАЦИОНАЛЬНЫЕ ОТНОШЕНИЯ (НА ПРИМЕРЕ НОВОСИБИРСКОЙ ОБЛАСТИ)
}

(C) Рубан Владимир Алексеевич

доктор экономических наук, профессор

E-mail: gmu@sgups.stu.ru

\section{(C) Цатурян Рена Вартгесовна}

обучающийся

E-mail: rena_tsaturyan@mail.ru

Сибирский государственный университет путей сообщения

Россия, 630049, г. Новосибирск, ул. Дуси Ковальчук, 191

В статье авторы исследуют эффективность реализации государственной национальной политики в регионе на основе анализа оценки межнациональных отношений. Приводятся результаты социологических данных по вопросу о состоянии межнациональных отношений в 2016 и 2019 г. Проведен анализ удовлетворенности населения региона работой органов власти в сфере межнациональных отношений. На основе эмпирического исследования делается вывод о том, что, признавая межнациональные отношения как стабильные, население Новосибирской области подчеркивает доминирующую роль властных структур в реализации национальной политики и необходимости тесного взаимодействия с институтами гражданского общества. Авторы приходят к выводу о том, что процесс формирования национальной политики не завершен и в настоящее время требует новых шагов, направленных на преодоление имеющихся проблем в сфере межнациональных отношений. В целях гармонизации межнациональных отношений выявлены приоритетные направления деятельности государственной власти в сфере национальной политики в Новосибирской области.

Ключевые слова: межнациональные отношения; национальная политика; этнические сообщества; этнокультурное многообразие; национально-культурная автономия; межэтнические отношения; полиэтничный субъект; этническая группа; анализ удовлетворенности.

\section{Для цитирования}

Рубан В. А., Цатурян Р. В. Анализ влияния государственной национальной политики на межнациональные отношения (на примере Новосибирской области) // Вестник Бурятского государственного университета. Экономика и менеджмент. 2020. № 3. С. 41-49.

В современной России вопросы государственного регулирования в сфере межнациональных отношений имеют серьезное стратегическое значение для укрепления гражданского единства населения страны, сохранения этнокультурного многообразия российской нации, достижения гражданского и межэтнического согласия, сохранения этнокультурного многообразия и безусловного приоритета национальных интересов регионов страны.

Этнические сообщества мобилизуются эффективнее, чем другие формы региональной самоорганизации, в связи с этим в 1990-2000 гг. федеральная межна- 
циональная политика в большей мере была делегирована регионам. Например, национальные республики Северного Кавказа и Поволжья получали большую часть межбюджетных трансфертов из федерального бюджета страны с учетом демократического и экономического потенциала их субъектов, чем регионы Сибири с доминирующим русским населением.

Новосибирская область (далее - НСО) является одним из крупнейших полиэтничных субъектов Российской Федерации. На территории области, по данным Всероссийской переписи населения 2010 г., проживает более 120 представителей этнических общностей ${ }^{1}$.

Важно отметить, что правовое обеспечение национальной политики является одним из ключевых механизмов, позволяющих реализовывать базовые ориентиры и подходы государственного управления в этой области.

Фундаментальные правовые основы национальной политики определяются, прежде всего, Конституцией РФ, в которой отражены основополагающие нормы: федерализм, принцип равноправия и самоопределения народов, гарантии прав индивида на национальную самобытность, права коренных малочисленных народов и национальных меньшинств ${ }^{2}$. Документом федерального уровня, утверждающим целевые установки, является Стратегия государственной национальной политики на период до 2025 г. $^{3}$, в которой одной из важных задач провозглашается сохранение и развитие этнокультурного многообразия народов РФ.

Одним из наиболее значимых правовых актов в сфере национальной политики выступает Федеральный закон от 17 июня 1996 г. № 74-Ф3 «О национальнокультурной автономии» ${ }^{4}$. С момента принятия данного закона прошло более двадцати лет. За это время национально-культурные автономии смогли добиться общественного признания. Например, в Новосибирской области зарегистрировано более 60 национально-культурных автономий, 27 из которых входят в состав Ассоциации национально-культурных автономий и организаций г. Новосибирска и Новосибирской области (далее - Ассоциация) [1]. Члены Ассоциации работают с национальными общинами, объединениями, землячествами, содействуют объединению представителей разных национальностей, сохранению национальных культур, проводят национальные праздники. Это свидетельствует об активном использовании гражданами данной формы самоорганизации.

Правовое регулирование национальной политики осуществляется также на уровне субъектов Федерации. Региональная власть наделена правом принимать нормативные акты в области осуществления национальной политики, в которых

\footnotetext{
1 Этноконфессиональный паспорт Новосибирской области [Электронный ресурс]. URL: https://etnopasport.nso.ru/, свободный (дата обращения: 10.08.20).

${ }^{2}$ Конституция Российской Федерации (принята всенародным голосованием 12.12.1993 с учетом поправок, внесенных Законами РФ о поправках к Конституции РФ от 30.12.2008 № 6-ФКЗ, от 30.12.2008 № 7-ФКЗ, от 21.07.2014 № 11-ФК3, 14.03. 2020 № 1-ФКЗ) // Собрание законодательства РФ. 2014. № 31. Ст. 4398.

${ }^{3}$ О Стратегии государственной национальной политики Российской Федерации на период до 2025 года: указ Президента РФ от 19.12.2012 № 1666 (ред. от 06.12.2018) // Собрание законодательства РФ. 2012. № 52. Ст. 7753.

${ }^{4}$ О национально-культурной автономии: федеральный закон от 17 июня 1996 г. № 74-Ф3 (ред. от 04.11.2014) // Российская газета. 1996. № 104. Ст. 92.
} 
В. А. Рубан, Р. В. Цатурян. Анализ влияния государственной национальной политики на межнациональные отношения (на примере Новосибирской области)

отражается специфика этносоциальной ситуации конкретного субъекта. В нашем случае это Распоряжение Правительства Новосибирской области от 22 апреля 2019 г. №151-рп «О Комплексном плане действий по гармонизации межэтнических отношений и реализации Стратегии государственной национальной политики Российской Федерации на период до 2025 года в Новосибирской области на 2019-2021 годы» ${ }^{1}$ Она содержит новые концептуальные подходы, не представленные в федеральной Стратегии. Это наглядно демонстрирует тот факт, что на региональном уровне правовое регулирование национальной политики возможно в целях не только трансляции установок федеральных властей, но и выработки собственных подходов.

Состояние межнациональных отношений выступает одним из значимых показателей для учета разработки нормативно-правовых актов. Межнациональные отношения - это совокупность субъективных отношений индивидуумов в социуме, которые либо принадлежат к разным национальностям, либо являются представителями различных этнических общностей [2, с. 47]. Важным аспектом анализа состояния межэтнических отношений региона является оценка активно действующих в нем этносоциальных субъектов.

Новосибирская область, несмотря на высокую долю одной этнической группы (по результатам последней переписи в 2010 г., 93,2 \% населения идентифицируют себя как русские $)^{2}$, тем не менее является формирующимся полиэтничным сообществом, обладающим своими особенностями и процессами [3]. Точно обозначить размеры этих сообществ затруднительно, поскольку в России отсутствует текущая статистическая информация об этническом составе населения РФ (точную оценку можно будет установить после переписи населения, которая запланирована на 2021 г.).

Динамика формирования межэтнического сообщества области в последние десятилетия носила неоднозначный характер, так же как и межнациональные отношения, для чего необходим анализ межнациональных отношений.

С этой целью был проведен опрос жителей $\mathrm{HCO}$ в период с 14 сентября по 15 октября 2019 г. Объект исследования: население старше 18 лет, постоянно проживающее в НСО. Метод проведения исследования: массовый опрос - формализованное онлайн-анкетирование. Выборка, использованная в ходе массового опроса по территориальному принципу, репрезентирует население НСО по месту проживания, полу, возрасту. Объем выборки - 280 респондентов. Для оценки состояния межнациональных отношений в НСО респондентам был задан следующий вопрос: «Как вы считаете, какие отношения сложились между людьми разных национальностей там, где вы живете?» (рис. 1).

\footnotetext{
${ }^{1}$ Национальная и религиозная политика // Министерство региональной политики Новосибирской области: официальный сайт [Электронный ресурс]. URL: https://minregion.nso.ru/page/6627, свободный (дата обращения: 10.08.20).

2 Этноконфессиональный паспорт Новосибирской области [Электронный ресурс]. URL: https://etnopasport.nso.ru/, свободный (дата обращения: 10.08.20).
} 


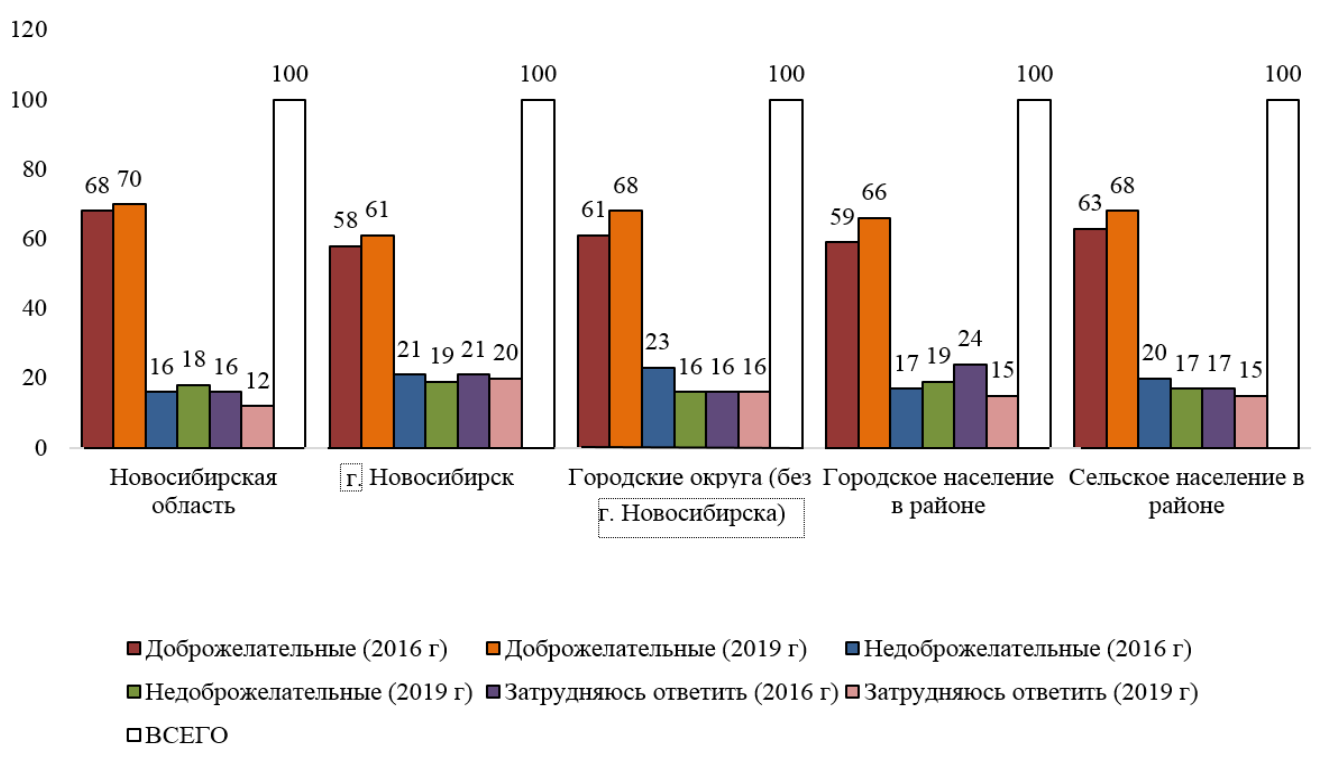

Рис. 1. Итоги опроса об отношениях между людьми разных национальностей в НСО (\% от всех опрошенных) [1]

Для определения среднего для области уровня терпимости по отношению к людям других национальностей важным является мнение жителей города Новосибирска, где численность населения составляет $61 \%$ общей численности жителей области. В селах уровень «доброжелательных» отношений выше, чем в городских округах. Это обусловлено тем, что наибольшая степень концентрации мигрантов сосредоточена именно в городских округах (Новосибирск, Бердск, Обь).

В среднем по России (по данным центра Фонда общественного мнения ${ }^{1}$ (далее - ФОМ) за 2018 год)) доля «недоброжелательных» отношений составляла $30 \%$. В городах с населением более 1 миллиона человек (Екатеринбург, Челябинск, Омск, Нижний Новгород, Волгоград) эта доля достигает 44\% (ФОМ), в Новосибирске - 8\%. Большинство входящих в исследование, проводимое по России, городов имеют более длительную историю межнациональных отношений, чем Новосибирск ${ }^{2}$. Тем не менее увеличение потока трудовых иммигрантов из Средней Азии повышает общую тревожность населения города и снижает ощущение личной безопасности в муниципальных образованиях области [1].

Для общей оценки межнациональных отношений в муниципальных образованиях НСО был задан вопрос: «Вы лично испытываете или не испытываете неприязнь к представителям какой-либо национальности?» (рис. 2).

\footnotetext{
${ }^{1}$ База данных «Фонд общественного мнения» [Электронный pecypc]. URL: https://fom.ru/, свободный (дата обращения: 10.08.20).

2 О мониторинге состояния межнациональных и межконфессиональных отношений [Электронный pecypc]. URL: fadn.gov.ru/system/attachments/attaches/000/026/137/ original/present_gis_3.09.pdf?1441744802, свободный (дата обращения: 10.08.20).
} 
В. А. Рубан, Р. В. Цатурян. Анализ влияния государственной национальной политики на межнациональные отношения (на примере Новосибирской области)

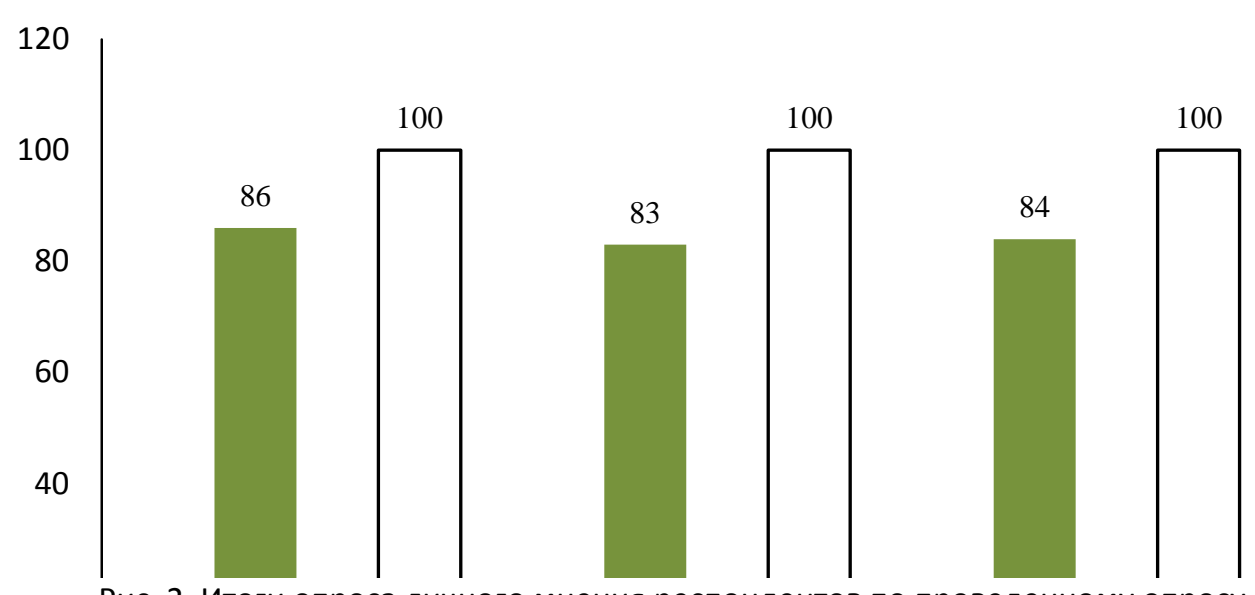

Рис. 2. Итоги опроса личного мнения респондентов по проведенному опросу

(\% от всех опрошенных)

86\% опрошенных жителей области полагают, что не испытывают раздражение по отношению к представителям других национальностей. Доля респондентов, испытывающих неприязнь к представителям разных национальностей в $\mathrm{HCO}$, составляет $13 \%$. По данным всероссийского исследовательского центра $\Phi \mathrm{OM}^{1}$, доля россиян, испытывающих неприязнь к людям другой национальности, в 2019 г. составляет 17\%, в НСО (по результатам проведенного исследования) $-11 \%$, что ниже среднего по стране.

По сравнению с данными 2016 г. оценки личной толерантности в 2019 г. изменились в лучшую сторону - $86 \%$ полагают, что не испытывают раздражение по отношению к представителям других национальностей. Также важно отметить, что доля респондентов, испытывающих раздражение/неприязнь к представителям разных национальностей в НСО, снизилась с 20 до $13 \%$. По-прежнему о своих негативных эмоциях чаще говорят жители городских округов (13-14\%).

По данным всероссийского исследовательского центра ФОМ, доля россиян, испытывающих неприязнь к людям другой национальности, составляет $17 \%$ (столько же в городах с населением свыше 1 млн человек). В Новосибирской области (по результатам проведенного исследования) - 15\%, а в городе Новосибирске - 20\%. Таким образом, показатель по НСО ниже среднего по стране, а в областном центре, напротив, выше, чем в среднем по городам, в которых население превышает 1 миллион человек [1].

В целях гармонизации межнациональных отношений, укрепления общероссийской гражданской идентичности и этнокультурного развития народов в РФ в рамках Стратегии государственной национальной политики РФ на период до 2025 г. на территории НСО реализуется Комплексный план действий по гармо-

\footnotetext{
${ }^{1}$ База данных «Фонд общественного мнения» [Электронный ресурc]. URL: https://fom.ru/, свободный (дата обращения: 10.08.20).
} 
низации межэтнических отношений и реализации Стратегии государственной национальной политики РФ на период до 2025 года ${ }^{1}$.

Исполнителями мероприятий Комплексного плана являются областные исполнительные органы государственной власти НСО, органы местного самоуправления $\mathrm{HCO}$, общественные объединения, правоохранительные органы и религиозные организации ${ }^{2}$.

Для определения эффективности деятельности органов исполнительной власти НСО в сфере межэтнических и межрелигиозных отношений также был проведен анализ удовлетворенности населения работой органов власти $\mathrm{HCO}$ в сфере межэтнических и межрелигиозных отношений. Это дает возможность определить, насколько правильно выбраны направления управленческой деятельности и какие она дает результаты на практике.

Исследование проведено в ноябре 2019 г. Объект исследования: население старше 18 лет, постоянно проживающее в НСО. Методы проведения исследования: массовый опрос жителей городов и районов НСО [1].

В процессе исследования мы установили, что деятельность региональных и местных властей в сфере межнациональных отношений жители области оценивают противоречиво. Часть респондентов видит работу властей, хотя и не всегда считает ее достаточной. Полностью удовлетворены работой власти в сфере межэтнических отношений $9 \%$ опрошенных, $26 \%$ удовлетворены частично (рис. 3 ).

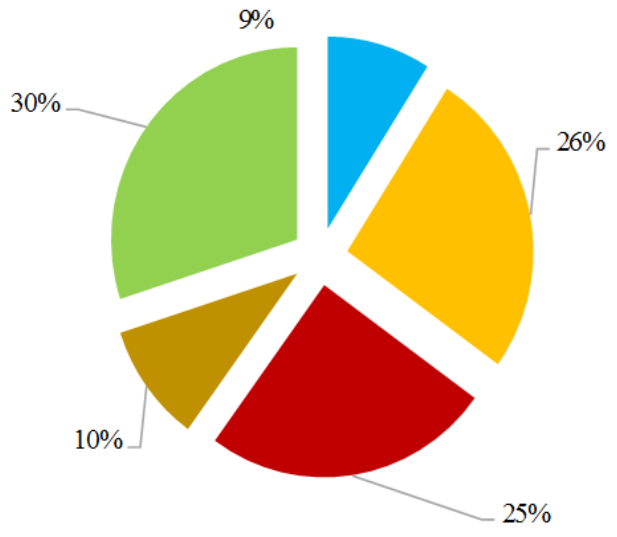

- Полностью удовлетворен

Скорее удовлетворен

- Скорее не удовлетворен

П Полностью не удовлетворен

- Затрудняюсь ответить

Рис. 3. Итоги опроса удовлетворенности работой органов власти НСО в сфере национальной политики в 2019 году (\% от опрошенных по НСО)

Негативно оценивающие деятельность властей жители (25\% скорее не удовлетворены, $10 \%$ полностью не удовлетворены) чаще всего отмечают бездействие властей в отношении большого потока мигрантов. Работа властей по со-

\footnotetext{
1 Этноконфессиональный паспорт Новосибирской области [Электронный ресурс]. URL: https:/etnopasport.nso.ru/, свободный (дата обращения: 10.08.20).

${ }^{2}$ Национальная и религиозная политика / Министерство региональной политики Новосибирской области: официальный сайт [Электронный pecypc]. URL: https://minregion.nso.ru/page/6627, свободный (дата обращения: 10.08.20).
} 
В. А. Рубан, Р. В. Цатурян. Анализ влияния государственной национальной политики на межнациональные отношения (на примере Новосибирской области)

зданию комфортных условий жизни для мигрантов в НСО также не всегда оценивается положительно коренными жителями.

Для решения проблемы низкой удовлетворенности работой властей респондентам был задан вопрос: «Какие меры необходимо предпринять властям для улучшения межнациональных отношений в $\mathrm{HCO} ? »$ (рис. 4).

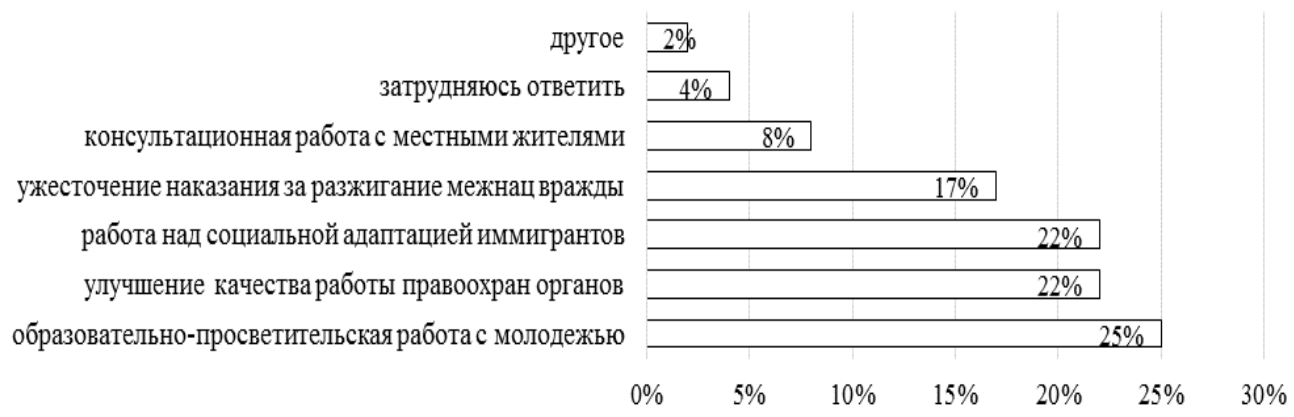

Рис. 4. Итоги опроса респондентов по улучшению межнациональных отношений в НСО

(\% от опрошенных по НСО)

Ранее нами был проведен анализ мнения респондентов о выборе необходимых мер, которые нужно предпринять властям для улучшения межнациональных отношений в НСО [1]. Для более полной оценки в данной статье были предложены дополнительные мероприятия.

Мы определили, что жители области чаще выбирают образовательнопросветительскую работу с молодежью, а также работу над социальной адаптацией иммигрантов и повышением безопасности (улучшение работы правоохранительных органов). Консультационная работа с местными жителями, по мнению опрошенных, менее эффективна - ее выбрали лишь 8\%. В графе «Другое» в ответе на вопрос был предусмотрен свой вариант ответа. Большинство из тех, кто его выбрал (около $2 \%$ от всех опрошенных), считает, что любые меры бесполезны, а приезжие должны уезжать обратно на родину.

С учетом проведенного нами анализа необходимо предложить дополнительные направления в деятельности национально-культурных организаций, которые могут быть усилены за счет более активного привлечения к их деятельности представителей разных национальностей. Работа национально-культурных автономий должна сопровождаться развитием институционального, культурного и ценностного плюрализма, которые помогут выработать чувство толерантности и уважения к другим точкам зрения среди членов различных этнических групп. Этого можно достичь путем тесного сотрудничества с органами государственной власти.

В рамках национальной политики на региональном уровне большое значение должно быть уделено не только проблемам адаптации мигрантов в области, но и проблемам русского населения как доминирующей национальной группы в межэтническом сообществе НСО [1].

Для совершенствования системы управления органами государственной власти в сфере межнациональных отношений авторы предлагают следующие мероприятия: 
a) организация занятий для школьников по укреплению межнациональных отношений и выработке толерантного отношения к представителям разных национальностей (необходимы специалисты);

б) освещение в средствах массовой информации культуры и традиций разных национальностей, населяющих $\mathrm{HCO}$, и распространение идей межнационального согласия;

в) поддержка деятельности общественных объединений муниципальных образований НСО, работающих в сфере гармонизации межнациональных отношений;

г) разработка системы мониторинга, контроля и предотвращения межэтнических и межконфессиональных конфликтов в местах компактного проживания в районах и городских округах НСО.

Таким образом, мы считаем, что в сфере национальной политики важно тесное взаимодействие с институтами гражданского общества, вовлечение всех заинтересованных структур и реализация национальной политики с учетом мнения жителей муниципальных образований. Применение предложенных мероприятий на практике позволит повысить уровень удовлетворенности населения работой органов власти в сфере межнациональных отношений.

\section{Литература}

1. Рубан В. А., Цатурян Р. В. Исследование государственной межнациональной политики (на примере Новосибирской области) // Социально-экономическое развитие России и Монголии: проблемы и перспективы: материалы VII Междунар. конф. Улан-Удэ, 2020. C. $197-200$.

2. Хохлов Ю. П. Предупреждение межнациональных конфликтов - стратегически важная задача государства // Прокурор. 2014. № 1. С. 47.

3. Попков Ю. В. Социокультурный мониторинг городского межэтнического сообщества: методология, методика. Новосибирск: Изд-во НГТУ-НЭТИ, 2018. 346 с.

\section{ANALYSIS OF THE INFLUENCE OF STATE NATIONAL POLICY ON INTERNATIONAL RELATIONS (THE CASE OF NOVOSIBIRSK OBLAST)}

Vladimir A. Ruban

Dr. Sci. (Econ.), Prof.

E-mail: gmu@sgups.stu.ru

Rena V. Tsaturyan

Student

E-mail: rena_tsaturyan@mail.ru

Siberian State Transport University

191 Dusi Kovalchuk St., Novosibirsk 630049, Russia

The article studies the effectiveness of implementing state ethnic policy in the region based on the analysis of interethnic relations estimation. We have presented the results of sociological study on the state of interethnic relations conducted in Novosibirsk Oblast in 2016 and 2019, the analysis of population satisfaction with the work of the authorities in the field of interethnic relations. The empirical research have shown that the population of the 

межнациональные отношения (на примере Новосибирской области)

region while recognizing interethnic relations as stable emphasizes the dominant role of the authorities in implementing national policy and the need for close cooperation with civil society institutions. Thus, we come to the conclusion that the process of national policy development is not completed and currently requires new measures aimed at overcoming the conceivable problems in the field of interethnic relations. In order to harmonize interethnic relations, we have identified the priority areas of the government activity in the field of national policy in Novosibirsk Oblast.

Keywords: interethnic relations; national policy; ethnic communities; ethnocultural diversity; national and cultural autonomy; interethnic relations; cosmopolitan entity; ethnic group; satisfaction analysis. 